\title{
GEORGIA WARM SPRINGS FOUNDATION
}

In 1924 the possible advantages of the natural facilities at Warm Springs, . Georgia, for the hydrotherapy treatment of the sequelae of infantile paralysis were brought to the notice of Franklin D. Roosevelt. In 1926, through Mr. Roosevelt's efforts, experimental work under expert supervision was begun and 23 patients were placed under observation for periods of 5 to 17 weeks. All seemed to improve.

Following this success, under Mr. Roosevelt's guidance the Georgia Warm Springs Foundation was organized in 1927 as a non-stock, non-profit organization to develop an institution at Warm Springs, Georgia, to render service to those handicapped by poliomyelitis. The purpose was two-fold ; first, to use the natural facilities of the springs and the skill of an able professional staff for the direct aid of patients ; second, to pass on to hospitals and the medical profession any useful observations and special methods of proven merit.

Warm Springs has the advantages of a pleasant climate and environment and an abundant supply of pure spring water. This is heated by Nature to almost $90^{\circ} \mathrm{F}$. as it flows from a depth of 1,500 feet at a constant rate of 800 gallons per minute, and is of such quality that no enervation results from remaining for considerable periods immersed in it. The water contains no magical curative properties nor does it have any particular medicinal qualities.

Historical records show that the first white settlers pushed westward from the east coast of Georgia, reaching the warm springs shortly after 1825. Until the early 1840's Warm Springs, about 75 miles south-west of Atlanta, was a post tavern on the military highway leading to Columbus, Georgia. The climate, the cool breezes and the remarkable pool of warm water soon made the place a favourite summer resort for the carriage trade of a large area. As the motor car came into favour, however, and people were able to travel greater distances more rapidly, Warm Springs declined in popularity as a resort and by 1924 was quite neglected.

In the early days of the Foundation, the natural facilities of the pool provided the mainstay of treatment. As the work progressed, it became necessary to supplement hydrotherapy with the full range and scope of modern treatment. Patients from every state in the United States have now been treated there as well as many from other countries including England, France and Germany.

As regards payment, patients are divided into three classes : those who can pay for their own care and treatment, part-aid patients and full-aid patients. About 200 beds are available. During 1945 there was an average of 35 patients from the armed forces under treatment who had contracted poliomyelitis in various parts of the world. In that year a total of 630 patients were treated at the Foundation for an average of 71 days each. Applicants not accepted are those receiving adequate treatment elsewhere and those not likely for any reason to benefit.

Confusion has arisen in the mind of the public as to the relationship between the Georgia Warm Springs Foundation and the National Foundation for Infantile Paralysis, Incorporated. These two foundations are entirely distinct. It was, however, on account of the experience gained at the Georgia Warm Springs Foundation that the National Foundation was created in 1938. While the Georgia Foundation has conducted an institution since 1927 for the treatment of children and adults suffering from the effects of infantile paralysis, the National Foundation attacks the whole problem of the disease through virus research, nutritional research, after-effects research, epidemic aid and study, and education.

(Extracted from What's New, January, 1947, published by Abbott Laboratories, N. Chicago, Illinois.)

We are delighted to announce the engagement and the forthcoming marriage of Miss Elizabeth Forder to Mr. David Hibbert. As Assistant Secretary to the Fellowship of Medicine, Miss Forder is well known to many of our readers throughout the world, and we believe they would join us in wishing her every happiness and success in her new venture. 